\title{
Effect of repetitive wrist extension with electromyography-triggered stimulation after stroke: a preliminary randomized controlled study
}

\author{
Yoseb Lee ${ }^{a}$, Yuri Cha ${ }^{b}$, Young Kim ${ }^{c}$, Sujin Hwang ${ }^{d}$, Yijung Chung ${ }^{e}$ \\ ${ }^{a}$ Department of Physical Therapy, Health and Welfare Graduate School, Sahmyook University, Seoul, Republic of Korea \\ ${ }^{b}$ Department of Physical Therapy, Sunlin University, Pohang, Republic of Korea \\ 'Department of ICT Convergence Rehabilitation Engineering, Soon Chun Hyang University, Cheonan, Republic of Korea \\ dDepartment of Physical Therapy, Division of Health Science, Baekseok University, Cheonan, Republic of Korea \\ e Department of Physical Therapy, College of Health Science and Social Welfare, Sahmyook University, Seoul, Republic of Korea
}

Objective: The purpose of this study was to explore the effect of repetitive wrist extension task training with electromyography (EMG)-triggered neuromuscular electrical stimulation (NMES) for wrist extensor muscle recovery in patients with stroke.

Design: Randomized controlled trial.

Methods: Fifteen subjects who had suffered a stroke were randomly assigned to an EMG-triggered NMES group ( $\mathrm{n}=8)$ or control group ( $\mathrm{n}=7)$; subjects in both groups received conventional therapy as usual. Subjects in the experimental group received application of EMG-triggered NMES to the wrist extensor muscles for 20 minutes, twice per day, five days per week, for a period of four weeks, and were given a task to make a touch alarm go off by activity involving extension of their wrist. In the control group, subjects performed wrist self-exercises for the same duration and frequency as those in the experimental group. Outcome measures included muscle reaction time and spectrum analysis. Assessments were performed during the pre- and post-treatment periods.

Results: In the EMG-triggered NMES group, faster muscle reaction time was observed, and median frequency also showed improvement, from 68.2 to $75.3 \mathrm{~Hz}$, after training $(p<0.05)$. Muscle reaction time was significantly faster, and median frequency was significantly higher in the experimental group than in the experimental group after training.

Conclusions: EMG-triggered NMES is beneficial for patients with hemiparetic stroke in recovery of upper extremity function.

Key Words: Electrical stimulation therapy, Electromyography, Stroke, Wrist

\section{Introduction}

For post-stroke individuals, wrist and finger extension motion, a key component of prehensile activity, is one of the most difficult motions to restore, and their force is important for rehabilitation [1]. Animal and clinical research studies have reported on active, repetitive, and task-related training as a critical requisite in promotion of motor recovery post stroke [2,3]. Several interventions for recovery of upper limb function encourage active, repetitive, and functional activity; these include constraint-induced therapy (CIT), robot-assisted movement, and electromyography (EMG)-triggered neuromuscular electrical stimulation (NMES), which encourage performance of active repetitive functional activities in post stroke patients [1,4-10]. However, these studies have some limitations. The CIT usually requires long-term treatment, and Robot-assisted therapy is expensive, the operation is complicated, and scientific evidence for its effect is still needed $[11,12]$.

NMES has been reported as a good therapeutic method

Received: 1 September, 2017 Revised: 21 September, 2017 Accepted: 22 September, 2017

Corresponding author: Yijung Chung

Department of Physical Therapy, College of Health Science and Social Welfare, Sahmyook University, 815 Hwarang-ro, Nowon-gu, Seoul 01795, Republic of Korea

Tel: 82-2-3399-1637 Fax: 82-2-3399-1639 E-mail: yijung36@syu.ac.kr

(c) This is an Open-Access article distributed under the terms of the Creative Commons Attribution Non-Commercial License (http://creativecommons.org/licens es/by-nc/4.0) which permits unrestricted non-commercial use, distribution, and reproduction in any medium, provided the original work is properly cited.

Copyright @ 2017 Korean Academy of Physical Therapy Rehabilitation Science 
for use with stroke patients who have difficulty in performance of active muscle contraction [13]. NMES is effective in reducing spasticity, strengthening muscles, increasing bone density, recovering range of motion, and affecting the sensorimotor cortex in the brain [14-18]. EMG-triggered NMES therapy augments volitional muscle contraction of stroke patients with a threshold set for each patient to reach by attempting to actively contract their muscles for a specific movement using electrical stimulation to assist the patient in completing performance of the task.

One study compared the effects of EMG-triggered NMES and cyclic NMES on improvement of hemiparetic upper extremity function recovery, especially on motor function of the wrist and finger extensor muscles [19]. EMG-triggered NMES was reported to be more effective in improving forearm extensor muscles [1,5,19-26]. Repetitive task performance is another method for augmentation of volitional muscle contraction in stroke patients. The quantity of training plays a key role in enhancing the therapeutic effect [27,28].

As mentioned previously, many researchers have studied the separate effects of EMG-triggered NMES and repetitive task training for stroke patients, however, only a few studies have focused on the combined effects of two experimental studies on stroke focusing on functional evaluations; not many of these have included study analysis of changes in muscle components or recruitment patterns by surface EMG. But it required that the study is composed of the physiological changes the muscle recruitment to use affordable training of active, repetitive, task-related training and EMGtriggered NMES. Thus, this study combined EMG-triggered NMES and repetitive task training in order to determine its effect on muscular changes and wrist motor recovery of post-stroke patients. The purpose of this study was to investigate the effects of EMG-triggered NMES with repetitive task training on recovery of wrist extensor muscles in patients with stroke.

The hypothesis of this study was that EMG-triggered NMES with repetitive training will have a greater effect on motor recovery of upper extremity, compared with conventional treatment for patients with hemiparetic stroke.

\section{Methods}

\section{Participants}

Participants were recruited from a rehabilitation center. Information of subject's recruitment was informed at rehabilitation center's announcement board for a week. After screening the volunteer under the inclusion criteria, eighteen subjects participated in the study after attaining a full understanding of the purpose and method of the research, and the signature consent form. Inclusion criteria were as follows: (1) first onset of an ischemic or hemorrhagic stroke confirmed by brain imaging; (2) below poor on manual muscle test of the less affected side; (3) able to perform volitional wrist extension greater than $10^{\circ}$ from the neutral position; and (4) no cognitive deficits (mini mental status examination $\geq 24$ ). Exclusion criteria included: (1) having a pacemaker or other metal implant stimulator; (2) unable to sit on a chair/wheelchair for longer than 20 minutes; and (3) other neurological or orthopedic deficits. All patients provided written informed consent. Table 1 shows the characteristics of subjects randomized into the EMG-triggered NMES and control groups.

\section{Experimental design}

This study had a single-blinded that the assessors were blinded about group assign, pretest-posttest control group design. Subjects were randomly assigned to the EMG-triggered NMES group $(n=9)$ or the control group $(n=9)$ using a computer-generated randomization list based on demographic characteristics of the subjects. Subjects in both groups participated equally in a regular therapeutic program

Table 1. Details on subjects in the study

$(\mathrm{N}=15)$

\begin{tabular}{lccc}
\hline \multicolumn{1}{c}{ Variable } & $\begin{array}{c}\text { EMG-triggered } \\
\text { NMES group }(\mathrm{n}=8)\end{array}$ & $\begin{array}{c}\text { Control } \\
\text { group }(\mathrm{n}=7)\end{array}$ & $p$-value \\
\hline Sex & & & \\
$\quad$ Male & 4 & 4 & 0.782 \\
$\quad$ Female & 4 & 3 & \\
Age (yr) & $55.3(16.4)$ & $62.0(12.3)$ & 0.385 \\
Weight (kg) & $59.2(7.6)$ & $59.4(8.5)$ & 0.908 \\
Height (cm) & $164.8(12.8)$ & $164.1(9.0)$ & 0.643 \\
Stroke type & & & \\
$\quad$ Ischemic & 4 & 3 & 0.782 \\
$\quad$ Hemorrhagic & 4 & 4 & \\
Affected side & & & \\
$\quad$ Left & 4 & 4 & 0.782 \\
$\quad$ Right & 4 & & \\
Post-stroke duration & $7.6(4.3)$ & $5.7(1.9)$ & 0.443 \\
(mo) & & & \\
MMSE (score) & $27.1(1.3)$ & $26.4(2.0)$ & 0.344 \\
FMA (score) & $19.0(11.3)$ & $20.5(11.3)$ & 0.861 \\
\hline
\end{tabular}

Values are presented as number only or mean (SD).

EMG: electromyography, NMES: neuromuscular electrical stimulation, MMSE: mini mental status examination, FMA: Fugl-Meyer assessment. 
(physical therapy, occupational therapy, and simple exercises), five times per week, for a period of four weeks. Subjects in the experimental group received additional task-oriented EMG-triggered NMES for 20 minutes, twice per day, five times per week, for a period of four weeks. Subjects in the control group were instructed to perform self-exercise of wrist extension during the same period. Participants were evaluated before and after training by two well-trained clinicians. Due to a change of address, the three subjects, one of the experimental group and two of the control group, dropped out prior to completion of treatment.

In addition to their conventional physical therapy, subjects in the EMG-triggered NMES group received wrist extensor training combined with EMG-triggered NMES and repetitive task training for 20 minutes twice per day, for a period of four weeks.

For repetitive wrist extensor training, a custom-made therapeutic table was prepared. The table had two straps with velcro attachments, which was located three to four $\mathrm{cm}$ before the elbow joint and three to four $\mathrm{cm}$ behind the wrist joint for binding of the affected forearm. A red-lighted touch alarm was placed on the middle of the table, so that it was between the hands of a subject. This alarm can identify changes when the sensor is touched by hand. A flexible metal stick was placed in front of the sensor, a $0.1 \mathrm{~kg}$ object was attached to it, and it was connected to the touch alarm. The table was flexed to the armrest of the chair or a wheelchair (Figure 1).

Subjects were instructed to sit on a chair or a wheelchair in a comfortable position, with the hip and knee flexed to $90^{\circ}$. The subject's wrist was strapped with velcro for fixation in neutral position of wrist joint. Three surface electrodes were placed on the extensor digitorum comminis and extensor carpi ulnaris muscles of the affected arm. An EMG-functional electrical stimulation (FES) 1,000 (Walking Man II; Cyber Medic Inc., Seoul, Korea) was used for EMG-triggered stimulation. The stimulation continued for five seconds. Biphasic frequency was set at $50 \mathrm{~Hz}$, with a pulse width of $200 \mu \mathrm{s}$, and the intensity ranged from 14 to $29 \mathrm{~mA}$. For each subject, a threshold for electrical stimulation was set at every training session according to his/her maximal voluntary extension power. Electrical stimulation using FES is triggered when muscle activation of voluntary wrist extension is above the threshold. Subjects then performed full extension of the wrist joint through EMG-triggered FES.

In addition to their conventional physical therapy, sub-

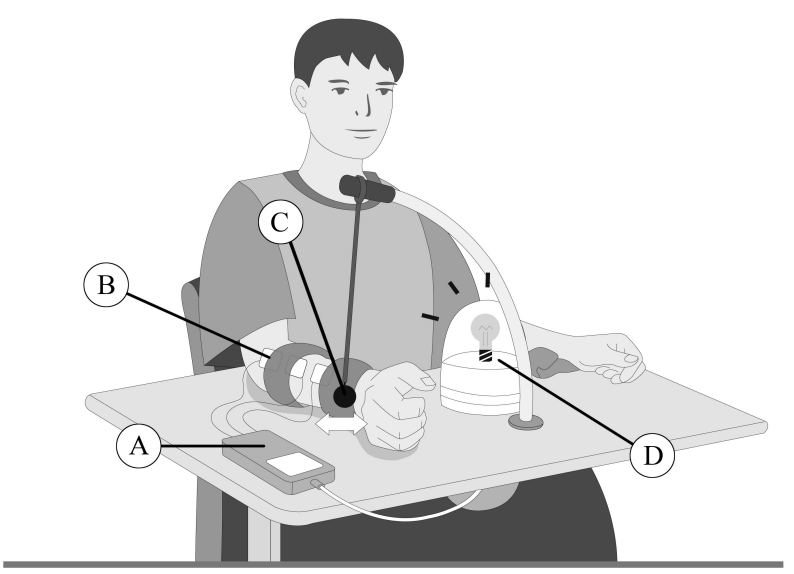

Figure 1. Custom-made therapeutic table for the EMG-triggered NMES training. (A) EMG-triggered NMES. (B) Electrodes with the strap. (C) The touch sensor with a flexible metal stick. (D) The red-lighted touch alarm. EMG: electromyography, NMES: neuromuscular electrical stimulation.

jects in the control group performed self-exercise on the wrist joint, for 20 minutes, twice per day. The exercise method was explained to the subjects and their care-takers, and a marking card was given out. The exercise included wrist extension and flexion, ulnar and radial deviation, stretching, and simple joint movement exercises.

\section{Outcome measures}

Two types of outcome measures were used for evaluation of functional improvement of wrist extensor. Surface EMG (Telemyo 2400T G2; Noraxon Inc., Scottsdale, AZ, USA) and myoRESEARCH XP Master Edition (Noraxon Inc.) were used for EMG data analysis. The sampling rate was set at $1,000 \mathrm{~Hz}$, bandwidth at 20 to $450 \mathrm{~Hz}$. A surface EMG electrode was placed one finger distance from the origin of the extensor communis digitorum, and another electrode was placed on the bulk of the extensor carpi ulnaris muscle. The extensor site was found on the arm, approximately five $\mathrm{cm}$ distal from the elbow. Electrodes were placed three to four $\mathrm{cm}$ apart in the center of the muscular mass that emerges, according to 'Cram's Introduction to Surface Electromyography' [29].

Each subject was instructed to sit comfortably and to place both hands on the table, which was adjusted to the proper height $\left(90^{\circ}\right.$ flexion on hip and knee joints). First, muscle reaction time was measured. Prior to measurement, the subject was instructed to respond as quickly as possible to the alarm sound. The alarm went off randomly in order to prevent any anticipation reactions. Measurements were per- 
formed three times for each subject, and the mean values were used for statistical analysis. EMT signal was first processed with full wave rectification, followed by low pass filter at $50 \mathrm{~Hz}$. The most stable 2.5-second period (block) before the beeper sound was sampled and set as the baseline for mean and standard deviation of the EMG signal amplitude. Muscle reaction time was calculated by selection of the first activation period that exceeded the threshold, and baseline wave with 3 standard deviation was then maintained for more than $25 \mathrm{~ms}$ [1,30]. Biopac AcqKnowledge ver. 3.7.1 (Biopac System Inc., Holliston, MA, USA) was used for analysis of muscle reaction time.

Median frequency was measured for spectrum analysis-window processing. The subject's wrist was extended manually by an examiner, and the subject was then instructed to resist the pressure and try to extend the wrist joint during a period of three seconds. Based on Fast Fourier Transform, the middle second in the three second period was sampled for spectrum analysis of the median frequency.

\section{Statistical analysis}

For statistical analysis, Wilcoxon signed rank tests were used for within-group comparisons and Mann-Whitney U-tests were used for between-group comparisons. The level of statistical significance was set at 0.05 . Chi-square tests were applied for evaluation of the difference in success rate and difference between the subject's opinions. SPSS ver.
12.0 (SPSS Inc., Chicago, IL, USA) was used for statistical analysis.

\section{Results}

\section{Muscle reaction time}

The reaction time and median frequency of before and after training are presented in Table 2. In the EMG-triggered NMES group, muscle reaction time showed a decrease, from 0.541 to $0.429 \mathrm{~ms}$, after training $(p<0.05)$. In comparison between the two groups, EMG-triggered NMES was found to be more beneficial $(p<0.05)$. No significant change was observed in the control group (Table 3 ).

\section{Median frequency}

Changes in median frequency were observed in both groups. Statistically significant improvement was observed only in the EMG-triggered NMES group after training (from $68.2 \mathrm{~Hz}$ to $75.4 \mathrm{~Hz}$ ). In comparison between the two groups, the EMG-triggered NMES group showed statistical improvement, compared to the control group $(p<0.05$; Table 3$)$.

\section{Discussion}

This study combined EMG-triggered NMES and repetitive task training, and determined its effects using surface EMG on motor recovery of the upper extremity in patients

Table 2. Individual scores measured in pre- and post-intervention

$(\mathrm{N}=15)$

\begin{tabular}{|c|c|c|c|c|c|c|c|c|c|}
\hline \multirow{2}{*}{ No. } & \multirow{2}{*}{ Group } & \multirow{2}{*}{$\begin{array}{l}\text { Age } \\
(\mathrm{yr})\end{array}$} & \multirow{2}{*}{ Sex } & \multirow{2}{*}{$\begin{array}{l}\text { Types of } \\
\text { stroke }\end{array}$} & \multirow{2}{*}{$\begin{array}{l}\text { Paretic } \\
\text { side }\end{array}$} & \multicolumn{2}{|c|}{ Reaction time (ms) } & \multicolumn{2}{|c|}{ Median frequency $(\mathrm{Hz})$} \\
\hline & & & & & & Pre-test & Post-test & Pre-test & Post-test \\
\hline 1 & Exp. & 50 & Male & Hemorrhage & Right & 0.537 & 0.368 & 45.900 & 55.700 \\
\hline 2 & Exp. & 65 & Female & Hemorrhage & Right & 0.329 & 0.381 & 110.500 & 119.000 \\
\hline 3 & Exp. & 69 & Male & Hemorrhage & Left & 0.341 & 0.283 & 78.400 & 75.500 \\
\hline 4 & Exp. & 38 & Female & Hemorrhage & Left & 0.741 & 0.660 & 54.650 & 65.200 \\
\hline 5 & Exp. & 80 & Female & Infarct & Left & 0.452 & 0.222 & 81.500 & 93.000 \\
\hline 6 & Exp. & 63 & Male & Infarct & Left & 0.349 & 0.267 & 62.100 & 66.700 \\
\hline 7 & Exp. & 45 & Female & Infarct & Right & 0.473 & 0.434 & 56.800 & 69.930 \\
\hline 8 & Exp. & 33 & Male & Hemorrhage & Right & 1.106 & 0.813 & 55.900 & 57.800 \\
\hline 9 & Cont. & 56 & Female & Hemorrhage & Right & 0.293 & 0.267 & 85.067 & 86.350 \\
\hline 10 & Cont. & 70 & Male & Hemorrhage & Right & 0.805 & 0.552 & 92.750 & 97.000 \\
\hline 11 & Cont. & 79 & Male & Hemorrhage & Left & 0.352 & 0.608 & 68.900 & 70.700 \\
\hline 12 & Cont. & 73 & Female & Hemorrhage & Left & 0.489 & 0.528 & 77.100 & 72.300 \\
\hline 13 & Cont. & 59 & Female & Infarct & Left & 0.478 & 0.455 & 74.150 & 83.200 \\
\hline 14 & Cont. & 45 & Male & Infarct & Left & 0.583 & 0.727 & 50.200 & 47.400 \\
\hline 15 & Cont. & 52 & Male & Infarct & Right & 0.244 & 0.566 & 69.730 & 69.200 \\
\hline
\end{tabular}

Values are presented as only number.

Exp.: electromyography-triggered neuromuscular electrical stimulation group, Cont.: control group. 
Table 3. Subject scores before and after intervention

$(\mathrm{N}=15)$

\begin{tabular}{|c|c|c|c|c|c|c|c|}
\hline \multirow[b]{2}{*}{ Scale } & \multicolumn{3}{|c|}{ EMG-triggered NMES group $(n=8)$} & \multicolumn{3}{|c|}{ Control group $(\mathrm{n}=7)$} & \multirow{2}{*}{$\begin{array}{c}\text { - Between } \\
\text { group } \\
(p \text {-value })\end{array}$} \\
\hline & Pre-test & Post-test & $\begin{array}{l}\text { Within } \\
\text { group } \\
(p \text {-value) }\end{array}$ & Pre-test & Post-test & $\begin{array}{l}\text { Within } \\
\text { group } \\
(p \text {-value) }\end{array}$ & \\
\hline Reaction time (ms) & $0.541(0.266)$ & $0.429(0.206)$ & $(0.025)$ & $0.463(0.192)$ & $0.529(0.142)$ & $(0.310)$ & $(0.040)$ \\
\hline Median frequency $(\mathrm{Hz})$ & $68.219(20.941)$ & $75.354(21.106)$ & $(0.025)$ & $73.985(13.505)$ & $75.164(15.817)$ & $(0.612)$ & $(0.040)$ \\
\hline
\end{tabular}

Values are presented as mean (SD).

EMG: electromyography, NMES: neuromuscular electrical stimulation.

with stroke. Results of the study showed a significant decrease in muscle reaction time and a significant increase in median frequency in the EMG-triggered NMES group, compared to the control group. The results of this study were in agreement with to those of previous studies showing effective results of EMG-triggered NMES training in stroke patients $[1,5,23,26]$.

Some previous research studies have examined the effects of EMG-triggered NMES by analysis of muscle reaction time and performance of the Box \& Block test. Subjects in the experimental group were significant increase in the number of block, which was moved compared with the control group. Due to abnormal distribution, a few of these studies used fractionated components of the reaction time [1,21-23]. Results of the study demonstrated that treatments with EMG-triggered NMES have the potential to decrease muscle reaction time. Results of our present study also provide evidence for the possibility of improvement in muscle reaction time of wrist extensor muscles.

There are two possible mechanisms to explain the efficacy. First, one of the motor recovery theories for stroke refers to the capacity of the motor system to perform a movement through multiple routes [31]. They reported that interactions in the sensorimotor system may result in achievement of a retroactivation of motor command on proprioceptive feedback activity from convergent regions. Proprioceptive feedback plays a critical role in motor planning by updating an internal model of the state and properties of the upper extremities [32]. Second, EMG-triggered NMES would increase the synaptic efficacy [33]. They reported that an increase of synaptic efficacy in existing neural circuits or formation of new synapses may be involved in the early stages of motor learning and that frequently repeated movements reinforce network connections. According to study results reported by Perez et al. [34], NMES was effective in inducing short-term plasticity in a spinally mediated recip- rocal Ia inhibitory circuit during performance of ankle joint movement in healthy subjects .

Results of this study also demonstrated a significant change in the median frequency. According to results of another study [35], the surface EMG of stroke patients showed lower median frequency in the affected tibialis anterior muscle fiber due to atrophied type II muscle fiber, compared to healthy subjects.

One study followed up on patients who had undergone anterior cruciate ligament reconstruction surgery three months previously; their EMG data were collected for analysis. Results of the study indicated muscle weakness in quadriceps even after pain relief, and a lowered median frequency [36]. According to Dattola et al. [37], a decrease in the amount of type II muscle was the reason behind lowered frequency; its inactivity, degeneration of motor neuron synapses, collateral reinnervation, and changes in motor unit components. Therefore, subjects who performed repetitive wrist exercise showed a significant increase in median frequency, compared with the control group, after the experiment, and this was due to recruitment of type II muscle. Sunderland et al. [38] also reported that repetitive task performance provides the physiological basis for motor learning in stroke patients, and is essential to overcoming movement disability. Bütefisch et al. [39] reported that repetition of a specific movement is a critical component of motor recovery in stroke patients. Repetitive training influences the functional recovery of synaptic plasticity, which includes alternative descending pathway, secondary motor area, and ipsilateral motor area [40-44]. Page et al. [45] recently reported that sufficient task-related training with electrical stimulation can elicit the largest and most consistent upper limb motor changes in stroke patients, compared to a lowfrequency exercise group or a sham group.

Results of this study indicated significant effects of EMG-triggered NMES and repetitive task performance on 
upper limb rehabilitation of stroke patients. However, due to a small number of subjects, the results may not be easily generalized. Most studies on motor recovery after stroke have suggested changes in neurons and plasticity of the brain; however, the results of the present study demonstrate physiological changes in muscle fiber using EMG analysis. Further research with a larger number of subjects, with an extended study period, and with electrical stimulation on various movements in the wrist is needed in order to determine its effects on motor recovery in patients with stroke.

\section{Acknowledgements}

This study was supported by Myoungji-Choonhey Rehabilitation Center.

\section{Conflict of Interest}

The authors declared no potential conflicts of interest with respect to the authorship and/or publication of this article.

\section{References}

1. Cauraugh J, Light K, Kim S, Thigpen M, Behrman A. Chronic motor dysfunction after stroke: recovering wrist and finger extension by electromyography-triggered neuromuscular stimulation. Stroke 2000;31:1360-4.

2. Taub E, Uswatte G, Pidikiti R. Constraint-Induced movement therapy: a new family of techniques with broad application to physical rehabilitation--a clinical review. J Rehabil Res Dev 1999;36:237-51.

3. Xerri C, Merzenich MM, Jenkins W, Santucci S. Representational plasticity in cortical area $3 \mathrm{~b}$ paralleling tactual-motor skill acquisition in adult monkeys. Cereb Cortex 1999;9:264-76.

4. Chae J, Fang ZP, Walker M, Pourmehdi S. Intramuscular electromyographically controlled neuromuscular electrical stimulation for upper limb recovery in chronic hemiplegia. Am J Phys Med Rehabil 2001;80:935-41.

5. Francisco G, Chae J, Chawla H, Kirshblum S, Zorowitz R, Lewis $\mathrm{G}$, et al. Electromyogram-triggered neuromuscular stimulation for improving the arm function of acute stroke survivors: a randomized pilot study. Arch Phys Med Rehabil 1998;79:570-5.

6. Hesse S, Schulte-Tigges G, Konrad M, Bardeleben A, Werner C. Robot-assisted arm trainer for the passive and active practice of bilateral forearm and wrist movements in hemiparetic subjects. Arch Phys Med Rehabil 2003;84:915-20.

7. Kimberley TJ, Lewis SM, Auerbach EJ, Dorsey LL, Lojovich JM, Carey JR. Electrical stimulation driving functional improvements and cortical changes in subjects with stroke. Exp Brain Res 2004;154:450-60.

8. Lum PS, Burgar CG, Shor PC, Majmundar M, Van der Loos M.
Robot-assisted movement training compared with conventional therapy techniques for the rehabilitation of upper-limb motor function after stroke. Arch Phys Med Rehabil 2002;83:952-9.

9. Taub E, Morris DM. Constraint-induced movement therapy to enhance recovery after stroke. Curr Atheroscler Rep 2001;3: 279-86.

10. Wolf SL, Lecraw DE, Barton LA, Jann BB. Forced use of hemiplegic upper extremities to reverse the effect of learned nonuse among chronic stroke and head-injured patients. Exp Neurol 1989;104:125-32.

11. Frick EM, Alberts JL. Combined use of repetitive task practice and an assistive robotic device in a patient with subacute stroke. Phys Ther 2006;86:1378-86.

12. Page SJ, Levine P, Sisto S, Bond Q, Johnston MV. Stroke patients' and therapists' opinions of constraint-induced movement therapy. Clin Rehabil 2002;16:55-60.

13. Santos M, Zahner LH, McKiernan BJ, Mahnken JD, Quaney B. Neuromuscular electrical stimulation improves severe hand dysfunction for individuals with chronic stroke: a pilot study. J Neurol Phys Ther 2006;30:175-83.

14. Bélanger M, Stein RB, Wheeler GD, Gordon T, Leduc B. Electrical stimulation: can it increase muscle strength and reverse osteopenia in spinal cord injured individuals? Arch Phys Med Rehabil 2000;81:1090-8.

15. Blickenstorfer A, Kleiser R, Keller T, Keisker B, Meyer M, Riener R, et al. Cortical and subcortical correlates of functional electrical stimulation of wrist extensor and flexor muscles revealed by fMRI. Hum Brain Mapp 2009;30:963-75.

16. Bowman BR, Baker LL, Waters RL. Positional feedback and electrical stimulation: an automated treatment for the hemiplegic wrist. Arch Phys Med Rehabil 1979;60:497-502.

17. Marqueste T, Hug F, Decherchi P, Jammes Y. Changes in neuromuscular function after training by functional electrical stimulation. Muscle Nerve 2003;28:181-8.

18. Pandyan AD, Granat MH, Stott DJ. Effects of electrical stimulation on flexion contractures in the hemiplegic wrist. Clin Rehabil 1997;11:123-30.

19. de Kroon JR, IJzerman MJ. Electrical stimulation of the upper extremity in stroke: cyclic versus EMG-triggered stimulation. Clin Rehabil 2008;22:690-7.

20. Bolton DA, Cauraugh JH, Hausenblas HA. Electromyogramtriggered neuromuscular stimulation and stroke motor recovery of arm/hand functions: a meta-analysis. J Neurol Sci 2004;223: 121-7.

21. Cauraugh JH, Coombes SA, Lodha N, Naik SK, Summers JJ. Upper extremity improvements in chronic stroke: coupled bilateral load training. Restor Neurol Neurosci 2009;27:17-25.

22. Cauraugh JH, Kim S. Two coupled motor recovery protocols are better than one: electromyogram-triggered neuromuscular stimulation and bilateral movements. Stroke 2002;33:1589-94.

23. Cauraugh JH, Kim SB. Chronic stroke motor recovery: duration of active neuromuscular stimulation. J Neurol Sci 2003;215: 13-9.

24. Gabr U, Levine P, Page SJ. Home-based electromyography- triggered stimulation in chronic stroke. Clin Rehabil 2005;19: $737-45$.

25. Hemmen B, Seelen HA. Effects of movement imagery and electromyography-triggered feedback on arm hand function in 
stroke patients in the subacute phase. Clin Rehabil 2007;21:58794.

26. von Lewinski F, Hofer S, Kaus J, Merboldt KD, Rothkegel H, Schweizer R, et al. Efficacy of EMG-triggered electrical arm stimulation in chronic hemiparetic stroke patients. Restor Neurol Neurosci 2009;27:189-97.

27. Duncan P, Studenski S, Richards L, Gollub S, Lai SM, Reker D, et al. Randomized clinical trial of therapeutic exercise in subacute stroke. Stroke 2003;34:2173-80.

28. Kwakkel G, Wagenaar RC, Koelman TW, Lankhorst GJ, Koetsier JC. Effects of intensity of rehabilitation after stroke. A research synthesis. Stroke 1997;28:1550-6.

29. Criswell E, Cram JR. Cram's introduction to surface electromyography. 2nd ed. Sudbury, MA: Jones and Bartlett; 2011. p. 412.

30. Di Fabio RP. Reliability of computerized surface electromyography for determining the onset of muscle activity. Phys Ther 1987;67:43-8.

31. Stein DG. Brain injury and theories of recovery. In: Goldstein LB, editor. Restorative neurology: advances in pharmacotherapy for recovery after stroke. Armonk, NY: Futura; 1998.

32. Ghez C, Gordon J, Ghilardi MF. Impairments of reaching movements in patients without proprioception. II. Effects of visual information on accuracy. J Neurophysiol 1995;73:361-72.

33. Asanuma H, Pavlides C. Neurobiological basis of motor learning in mammals. Neuroreport 1997;8:i-vi.

34. Perez MA, Field-Fote EC, Floeter MK. Patterned sensory stimulation induces plasticity in reciprocal ia inhibition in humans. $\mathrm{J}$ Neurosci 2003;23:2014-8.

35. Toffola ED, Sparpaglione D, Pistorio A, Buonocore M. Myoelectric manifestations of muscle changes in stroke patients. Arch Phys Med Rehabil 2001;82:661-5.

36. Drechsler WI, Cramp MC, Scott OM. Changes in muscle strength and EMG median frequency after anterior cruciate liga- ment reconstruction. Eur J Appl Physiol 2006;98:613-23.

37. Dattola R, Girlanda P, Vita G, Santoro M, Roberto ML, Toscano A, et al. Muscle rearrangement in patients with hemiparesis after stroke: an electrophysiological and morphological study. Eur Neurol 1993;33:109-14.

38. Sunderland A, Tinson DJ, Bradley EL, Fletcher D, Langton Hewer R, Wade DT. Enhanced physical therapy improves recovery of arm function after stroke. A randomised controlled trial. J Neurol Neurosurg Psychiatry 1992;55:530-5.

39. Bütefisch C, Hummelsheim H, Denzler P, Mauritz KH. Repetitive training of isolated movements improves the outcome of motor rehabilitation of the centrally paretic hand. J Neurol Sci 1995;130:59-68.

40. Aizawa H, Inase M, Mushiake H, Shima K, Tanji J. Reorganization of activity in the supplementary motor area associated with motor learning and functional recovery. Exp Brain Res 1991;84: 668-71.

41. Chollet F, DiPiero V, Wise RJ, Brooks DJ, Dolan RJ, Frackowiak RS. The functional anatomy of motor recovery after stroke in humans: a study with positron emission tomography. Ann Neurol 1991;29:63-71.

42. Di Piero V, Chollet FM, MacCarthy P, Lenzi GL, Frackowiak RS. Motor recovery after acute ischaemic stroke: a metabolic study. J Neurol Neurosurg Psychiatry 1992;55:990-6.

43. Freund HJ, Hummelsheim H. Lesions of premotor cortex in man. Brain 1985;108:697-733.

44. Fries W, Danek A, Scheidtmann K, Hamburger C. Motor recovery following capsular stroke. Role of descending pathways from multiple motor areas. Brain 1993;116:369-82.

45. Page SJ, Levin L, Hermann V, Dunning K, Levine P. Longer versus shorter daily durations of electrical stimulation during taskspecific practice in moderately impaired stroke. Arch Phys Med Rehabil 2012;93:200-6. 